\title{
Supplier's view of water demand for a city: modelling the influencing factors
}

\author{
C. Fodya \& C. Harley \\ University of the Witwatersrand, Johannesburg, South Africa
}

\begin{abstract}
An efficient system operates at equilibrium. Likewise, in the water business, companies aim to produce just enough water to match what is being demanded by its consumers. While consumers perceive income and price elasticity as their main influencing factors to water demand, suppliers have a different see altogether, and their factor differ from city to city. For example, Zomba City's supply company, Southern Region Water Board, lists daily and seasonal consumption fluctuations as well as population dynamics as its three major influencing factors to determine demand for water. This paper presents a model to predict water demand for Zomba city as influenced by the three aforementioned factors. With daily consumption data for Zomba City recorded from 2009 to 2013, and converted to standard hourly data by the weighting method, the parameters for daily fluctuations, seasonal fluctuations as well as population dynamics were determined. Sums of 24 hourly data readings generated from the model were compared with the daily recordings and a linear relationship was observed. In terms of predicting, the model is able to show that the existing infrastructure can sustain the current population, at least at the current growth rate for the next 17.8 years and that the reservoir, Mulunguzi Dam, has enough water for not only the city but the whole Zomba District for the next 5,500 years also. Equally, such capacity has the potential to supply the whole Malawi population for the next 42 years.
\end{abstract}

Keywords: water demand, water consumption, demand influencing factors.

\section{Introduction and background}

The law of demand and supply dictates that any business system should be operated at equilibrium. In fact, a measure of how deviated a system is away from its equilibrium is a good indicator of its efficiency. In water business, for example, a 
supplier's intent is to produce water just enough to meet the demand. If less water than demanded is produced, consumers experience persistent water shortages as rationing has to be employed. If too much is produced, suppliers running costs (from wasted energy, chemicals, man power and other input resources) become high.

The need for a supplier to thoroughly understand its demand requirements cannot be overemphasized. It is as vital as the consumer's understanding of the same which is extensively explored in literature. Such an understanding helps the supplier to make appropriate decisions for its operations like to demarcate limits between peak hours and off-peak hours, to map out communities demand needs, as well as to determine appropriate pricing methods.

Until late, much of literature approaches demand for water in communities from a consumer's perspective [1-7]. Under this approach, the major influencing factors to demand for water are household income as well as price elasticity of the water. In a typical situation, a household is willing to spend a certain fraction of its income on water. Some communities have been reported to devote a big percentage of their income (perhaps, that explains why water disconnections are rampart in other communities). On the other hand, water demand has been found to be of little to no elasticity to pricing. This means, as a necessity, communities are willing to spend more, if not anything they have, on water irrespective of how pricing is varying.

In spite of all this, there is very little literature that tackles the demand from a supplier's perspective. At the end of the day, what is produced must match what is demanded by the consumers. This is vital for the planning how much to produce in the next period of time to match the consumer demand. For example, $[2,5,7]$ used multivariate analysis, artificial neural networks and time series analysis respectively to predict short term demand of up to a couple of weeks. There is however need to go beyond just an hour, or a day, or just weeks. For planning purposes it is essential to have an idea of how the demand will be in the next five years, or when the existing infrastructure (e.g. tanks, treatment plant) becomes inadequate to the population.

When simulating network flow, supply is usually modelled by parabolic functions which lack the repetitive nature of the behaviour [8-16].

Unlike consumers, producers' influencing factors to quantity of water demanded are different from income and price elasticity, and they vary from community to community. For example, Zomba City's Water Supply Company, Southern Region Water Board, mentions daily fluctuations, seasonal fluctuations and population dynamics as its main influencing factors for its production (Figure 1).

Water consumption is high during day time when compared to night time. This means more water must be produced during day time. Same pattern is observed with seasons. Water demand is high in dry season than in rainy season. The Supply Company mentions availability of other sources of water like seasonal rivers, and rain harvested water as an explanation to the low demand during rainy season. On the population dynamics, it is evident that more water will be demanded with increasing population size, household numbers, improved living standards, just to mention a few. 


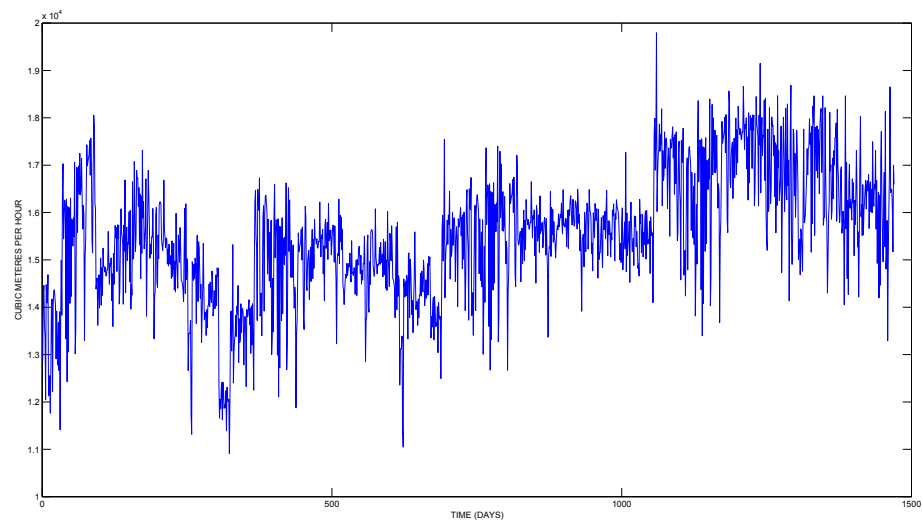

Figure 1: Consumption readings for a period of four years.

The main aim of this paper is to present a mathematical model that depicts demand for water in Zomba City as a function of the three influencing factors as proposed by the Supply Company. Specifically, the objectives of coming up with this model are to incorporate the relationship between water demand in a single day, water demand in season cycles as well as population dynamics. It is expected that this model will be able to capture the observed patterns namely more water demanded during day than at night, more water demanded during dry season than rainy, as well as in increase in water demanded with increase in population size and number households. This model must also be able to predict the demand levels which becomes inputs in decision making for the improvement of the supply network.

Zomba is the old Capital of Malawi and is the major source of revenue to Southern Region Water Board. Of the twelve districts the Board is mandated to supply water, $70 \%$ of its revenue comes from Zomba City alone. The city has a reservoir, Mulunguzi Dam, sitting on top of mount Zomba and able to supply up to 3,55 million cubic meters of water at any time. Being a mountainous city, $95 \%$ of its network is gravity fed. Yet only $88 \%$ of its population have access to piped water [17]. Before any improvement can be done on the city's network, it is important to first understand the demand needs of the city. This is essentially what this paper covers. The rest of the network improvements will be covered in subsequent papers to come.

The rest of the paper is outlined as follows: The next section presents the proposed model with all necessary simplifications. Next is the methodology section which describes how, when and why was the data collected. Fitting of the data into the proposed model is explained in the Results section where the outcomes are mention. The Results section is followed by the Discussion section which fits the current work into the knowledge base and proposes future research 
alternatives to the work in the paper. Finally, a conclusion section summarises the whole work of the paper.

\section{The water consumption model}

Zomba City Supply lists daily fluctuations, seasonal fluctuations, as well as population dynamics as its main influencing factors.

A simple model to capture the relationship between water production and daily fluctuations is the sine model or the cosine model. Choice about which one of the two to use depends on the problem at hand. In our case, for example, since standard data for modelling water consumption statistics is counted from the beginning if the day, at midnight, and coincidentally consumption figures are low at that time, then a sine model would be ideal. If we were interested in the differential of the consumption model, a cosine model can be used.

Similarly, the repeating pattern during dry and wet seasons can also be modelled by a sine or cosine model. However, since annual consumption data is recorded from the month of July, which is in dry season and consumption levels are high, a cosine model would be more suitable.

In the case of a population dynamics, the number of households and the status of living standards for the population are the good indicators. However, according to data [17-19] these are pegged constant to the population size, thus making it the indicator to be considered when modelling. A logistical Population Growth model is used.

The following model is proposed:

$$
\frac{d U}{d t}=\beta+\eta^{*} \cos \left(\omega_{1} t\right)+\zeta^{*} \sin \left(\omega_{2} t\right)+\kappa \frac{d P}{d t}
$$

where

- $U=U(t)$ is the consumption, or demand, function of time $t$,

- $P=P(t)$ is the population function of time with $P_{0}$ the initial population,

- $\omega_{1}$ is the short term (in our case, daily) fluctuation frequency, with period $T=24$ hours

- $\omega_{1}$ is the long term (in our case, seasonal) fluctuation frequency, with period $T=365$ days, and

- $\beta, \eta^{*}, \zeta^{*}$ and $\kappa$ are constants.

From literature, we have that

$$
\frac{d P}{d t}=\gamma P\left(1-\frac{P}{K}\right)
$$

where $\gamma$ is the population growth rate and $K$ is the carrying capacity of the medium (in our case, the maximum population Zomba City can contain). 
Inserting (2) into (1) and integrating both sides gives

$$
U(t)=\alpha+\beta t+\eta \sin \left(\omega_{1} t\right)+\zeta \cos \left(\omega_{2} t\right)+\kappa \frac{K}{1+A e^{-\gamma t}}
$$

where $\alpha, \eta=\frac{\eta^{*}}{\omega_{1}}, \zeta=\frac{\zeta^{*}}{\omega_{2}}$, and $A=\frac{K-P_{0}}{P_{0}}$ are constants.

Finally, we will have to simplify the model as much as possible but without losing much of its value. A possible approach is to take the limit of the function $U$ as $t \rightarrow \infty$. It is important to note that

$$
\lim _{t \rightarrow \infty} \frac{K}{1+A e^{-\gamma t}}=\frac{K}{1+0}=K
$$

Inserting the results from (4) into (3), we have the following:

$$
U(t)=\Lambda+\beta t+\eta \sin \left(\omega_{1} t\right)+\zeta \cos \left(\omega_{2} t\right)
$$

where $\Lambda=\alpha+\kappa K$.

An interesting result from the simplification is that while the second and the third terms of the right hand side of the model carter for the short term and long term fluctuations respectively, population dynamics is taken care of by the linear term.

\section{Methodology}

Data on daily production readings from the Treatment Works Plant for Zomba City, spanning July 2009 to June 2013, were obtained from Southern Region Water Board's Zomba office. To conform to the standard data used in literature, twenty-four hourly readings for a period of seven days were taken in the second week of September 2012. Based on average weighting method, daily readings were distributed across the twenty-four hour period.

With an average of 4.4 persons per household in the Southern Region of Malawi [17], and that the percentage of the population having access to piped water according to 1987,1998 as well as 2008 census reports being constant at $80 \%$, population size is a good indicator to work with as knowing the population size determines how many households are available as well as how many households or people have access to piped water [17-19].

Both daily and hourly production data were independently fitted into the developed mathematical model and the corresponding parameters for the daily fluctuations, seasonal fluctuations as well as population dynamics were obtained for each of the two . The resulting functions with their associated parameters were compared to the raw daily readings obtained from Zomba. Readings generated by hourly model were summed in twenty-four hourly intervals and compared to the raw daily readings. 


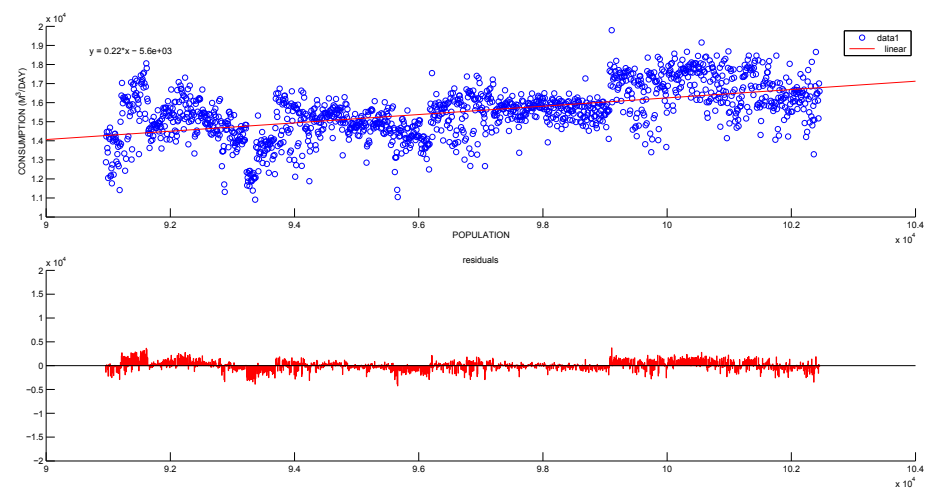

Figure 2: Linear relationship between population growth and consumption.

\section{Results}

\subsection{Pop growth and consumption}

As previously mentioned, the linear term in the derived model takes care of the population growth effect on the consumption. It is interesting to note that a simple MATLAB run of linear regression analysis of the two - consumption against population growth - is in agreement with the model (Figure 2).

\subsection{Model fitting}

The data fitting process into the model was done in two parts: the daily recording fit, as well as hourly recordings fit. This was done with only changing the values of the frequencies. In the case of daily recordings fitting, the periods used were 1 day and 365 days respectively. Thus $\omega_{1}$ and $\omega_{2}$ were assigned the values of 1 and $\frac{1}{365}$ respectively. With hourly recordings fitting, $\omega_{1}$ and $\omega_{2}$ take the values $\frac{1}{24}$ and $\frac{1}{24 \times 365}$ respectively.

MATLAB's curve fitting toolbox was used to come up with the two specific models for the daily as well as hourly models.

The Daily and Hourly Models, as derived by the data fitting procedure are as follows:

$$
\begin{aligned}
& U_{D}\left(t_{D}\right)=14239+2 t_{D}-76 \sin \left(t_{D}\right)+13 \cos \left(\frac{t_{D}}{365}\right) \\
& U_{H}\left(t_{H}\right)=594+0.003 t_{H}+0.997 \sin \left(\frac{t_{H}}{24}\right)+0.3418 \cos \left(\frac{t_{H}}{24 \times 365}\right)
\end{aligned}
$$

where $t_{D}$ is time in days and $t_{H}$ is time in hours. 


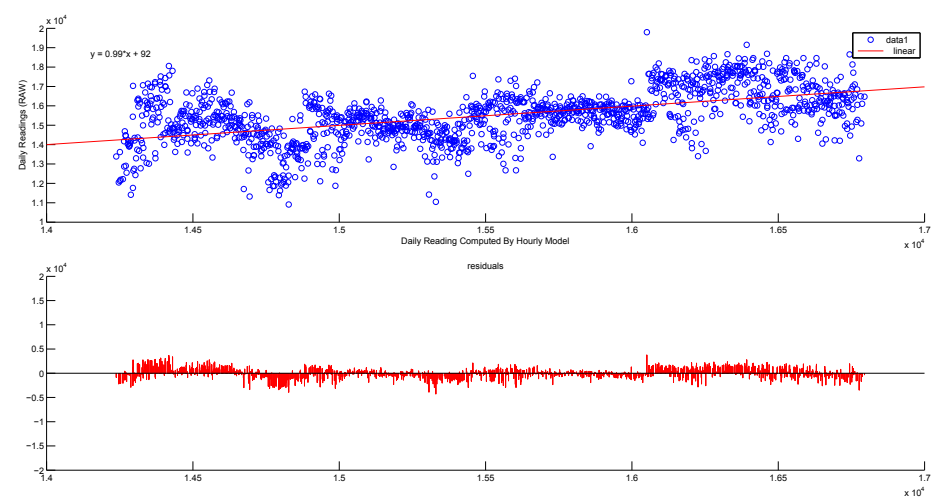

Figure 3: Linear relationship between raw daily readings and daily readings from the Hourly Model.

\subsection{The Hourly Model}

The Hourly Model was used to generate hourly data over the whole four year period in which raw readings were recorded. The generated readings were added in successive 24 hours to come up with daily recordings for comparison with the actual daily readings. A linear regression for the raw daily readings against those generated by summed up from the Hourly Model was run. A linear relationship was the observed. (In fact for any fitting beyond linear, MATLAB would complain about the polynomial being badly conditioned. For cubic and beyond, the resulting curve is actually progressing downward.) (Figure 3).

\subsection{The daily model}

When raw daily recordings are fitted with a linear model, the function returned is $U_{\text {Raw Fitted }}=14252+1.7003 t_{D}$. It is interesting to note how the coefficients of the just mentioned function and those of the linear term from the $U_{D}$ function are almost the same. This means the linear fit for the raw data is nothing but the population component of the model. So the only difference is the short and long term fluctuations which are captured by the model and not the former.

With the current production capacity of 27000 cubic metres per day from Zomba Treatment Works Plant, it will take about 17.8 years for the plant to become inadequate for the demand, at least with the current growth rate of the population.

The current water reservoir, the Mulunguzi Dam, which has a capacity of 3.35 million cubic meters of water may be able to supply the city for at least the next 4569 years after which the current capacity would become the demand per day for the city. However, considering the maximum recorded population density of 16, 205 persons per square kilometre (in Monaco) [20], the current population of not only Zomba City but the whole Zomba District which was at 600,000 in 2009, 
and the current growth rate of $3 \%$ [21], Zomba would attain its maximum carrying capacity of 42 million people in the next 142 years. This is well within the capacity of the dam to supply enough water to every resident of the district. Alternatively, the Dam can supply the whole Malawi population for the next 42 years.

\section{Discussion}

Now that we have a model that is able to predict consumption levels for Zomba City, it is essential to note that such ability can help improve efficiency in the production of water for the city demand. This efficiency goes beyond the planning for consumption only. It also comes in handy when planning for infrastructure expansion. For example, the City ought to plan for expansion of its Water Treatment Plant in the next 15 years also, so that by the time the existing plant becomes inadequate, there is already a support for the extra demand. Issues of water rationing can never be experienced if proper pannings are done and executed in time.

As can also be deduced from the model, there is supposed to be enough piped water available to every resident of Zomba City as well as Zomba District. Even with the current setup of existing reservoir and treatment plant, Zomba has enough water for the city for at least 15 years. This is in agreement to the fact that, as a city in SubSaharan Africa, Zomba is affected by the economic water scarcity, as compared to physical water scarcity [22-24]. It just requires efficient management of the existing infrastructure, and the structure can supply to much more people than what it is able to do currently. This means further positive research on efficient management of the supply systems can be essential to cities like Zomba. The same can be extended to different cities in the region while acknowledging the influencing factors may differ from city to city. In the end, when we have more efficient water distribution systems, the millennium development goal (MDG) of access to safe drinking water will be achieved in the region which sees acute problem with water $[25,26]$.

Hourly data readings had to be derived from daily readings. Effectiveness of the model can be greatly improved if we had the exact hourly readings recorded. Also, a suggestion that the hourly readings be taken at the Treatment Works Plant, at both end of the Tanks (inflow and outflow) and at the consumers' end (usually can be obtained from utility bills) can help determine which area of the network is more inefficient than the others. Targeting such areas will have a great impact on the efficiency of the systems.

Finally, the model is built on the understanding of the prevailing factors that affect the city's water demand. As cities have different factors affecting their demand needs, the model may differ from city to city although the three mentioned factors in Zomba are bound to have an effect to almost every city. So it is important to consider each city individually. For example, adding the noise term to the model may help in defining and capturing inefficiencies. The proposed model in this paper is, however, a good and simple starting point to understand the demand needs 
for cities, as well as a beginning step towards making water systems more efficient in areas they are needed most at the moment.

\section{Conclusion}

This paper has presented a new mathematical model for determining demand or consumption of water in a typical city. Unlike the previous models which capitalized on the household's influencing factors to water demand namely income and price elasticity, this model takes into consideration the supplier's view. For example, in Zomba City, Malawi, the supplier mentions daily and seasonal consumption fluctuations as well as population dynamics as the major influencing factors. With the constant ratio of 4.4 persons per household and a constant percentage of $80 \%$ of population having access to piped water, population size is a good indicator to work with. Daily consumption data for four years since 2009 was collected from Southern Region Water Board's Zomba Office. To conform with the standard data in literature, hourly data for seven days was recorded and the daily consumption data was converted into hourly data using the weighting methods. Both daily and hourly data were fitted into the model separately and the corresponding parameters were calculated using MATLAB. The corresponding daily as well as hourly models gave convincing results. For example, at the current population growth rate, the existing treatment plant can serve the population for the next 17.8 years, and the current Mulunguzi Water Dam has over 4,500 years to serve the entire Zomba District population. An interesting contribution of this paper to the knowledge base is the fact that suppliers have different view of their demand needs. What consumers consider as their influencing factors to water demand are completely different from what suppliers see. It must also be mentioned that the influencing factors for Zomba are not exclusive, which means they may differ from city to city.

\section{References}

[1] Arbues F., Garcia-Valinas M., Martinez-Espineira R., Estimation of Residential Water Demand: a State-of-the-art Review, Journal of SocioEconomics, Vol 32 (2003) pp 81-102

[2] Babel M.S., Das Gupta A., Pradhan P., A Multivariate Econometric Apporoach for Domestic Water Demand Modelling: An Application to Kathmandu, Nepal, Journal of Water Resources Management, Vol 21 (2007) pp 573-589

[3] $\mathrm{Mu}$ X., Whittington D., Briscoe J., Modelling Village Water Demand Behaviour: A Discrete Approach, Journal of Water Resources Research, Vol 26 (1990) pp 521-529

[4] van Zyl J.E., Haarhoff J., Husselmann M.L., Potential Application End-Use Demand Modelling in South Africa, Journal of the South African Institution of Civil Engineers, Vol 45 (2003) pp 9-19 
[5] Hanke S.H., de Mare L., Residential Water Demand: A Pooled, Time Series, Cross Section Study of Malmo, Sweden, Water Resources Bulletin - American Water Resources Association, Vol 18, No. 4 (1982)

[6] Worthington A.C., Hoffman M., An Empirical Survey of Residential Water Demand Modelling, Journal of Economic Surveys, Vol 22 (2008) pp 842871

[7] Jain A., Varshney A.K., Joshi U.C., Short-Term Water Demand Forecast Modelling at IIT Kanpur Using Artificial Neural Networks, Journal of Water Resources Management, Vol 15 (2001) pp 299-321

[8] Vladmir C., Heilio M., Krejic N., Nedeljkov M., Mathematical Model for Efficient Water Flow Management, Advances in Engineering Software, 2008

[9] Baran B., Lucken von C., Sotelo A,. Multi-Objective pump scheduling optimisation using evolutionary Strategies, Advances in Engineering Software, 2005, vol. 36, pp 39-47

[10] Benedict P.R., Fundamentals of Pipe Flow, John Wiley and sons, Inc, 1980

[11] Mays L.W., Water Distribution Systems Handbook, McGraw-Hill, Michigan, 2000

[12] Burgschweiger J., Gnadig B., Steinbach M., Optimization Models for Operative Planning in Drinking Water, ZIB-Report, Berlin, 2004

[13] Izquierdo J., Perez R., Iglesias L.P., Mathematical Models and Methods in Water Industry, Mathematical and Computer Modelling, 2004, vol. 39, pp 1353-1374

[14] Jeppson R.,Analysis of flow in pipe networks, Ann Arbor Science Publisher Inc., Michigan, 1976

[15] Lansey K.E., Awumah K., Optimal pump operations considering pump switches, Journal of Water Resources and Planning Management, 1994

[16] Srinivas N., Deb K., Multi objective optimization using non-dominated sorting genetic algorithms, Evol Comput, 1994, pp 221-248

[17] National Statistics Office, Malawi, 2008 Population Census Report, http://www.nsomalawi.mw, accessed Nov 2013

[18] National Statistics Office, Malawi, 1987 Population Census Report, http://www.nsomalawi.mw, accessed Nov 2013

[19] National Statistics Office, Malawi, 1998 Population Census Report, http://www.nsomalawi.mw, accessed Nov 2013

[20] World Atlas, Countries of the World: By highest population density, http://www.worldatlas.com/aatlas/populations/ctydensityh.htm, accessed Nov 2013

[21] Zomba City Council, Zomba District Socio-Economic Report 2009-2012, http://http://www.zombadistrict.mw/downloads/zomba-sep.pdf, accessed Nov 2013

[22] Wikipedia, Water Scarcity, en.wikipedia.org/wiki/water-scarcity, 2012

[23] The Water Project Goal, Physical and Economic Water Scarcity, www.thewaterprojectgoal.org/water-scarcity-2.asp, 2012

[24] The Business Week, Effects of Water Scarcity on Business, www.businessweek.com/bwdaily/duflash/feb2009/ 
[25] World Health Organization,WHO Report, 2000

[26] United Nations Organization,UN Report, 2000 